\title{
Fluorescence of Oxidized Flavoproteins from Perifused Isolated Pancreatic Islets
}

\author{
U. Panten and H. Ishida \\ Pharmakologisches Institut der Universität Göttingen, Göttingen, Federal Republic of Germany \\ Received: July 16, 1975, and in revised form: September 9, 1975
}

\begin{abstract}
Summary. In perifused pancreatic islets, the fluorescence of oxidized flavoproteins (FAD) was recorded continuously. Elevation of glucose concentration in the medium from 0 or $5 \mathrm{mM}$ to $20 \mathrm{mM}$ led to decrease in FAD-fluorescence beginning $10 \mathrm{sec}$ after change of medium. L-leucine (10 mM), ( \pm$)-b-B C H ~(20 \mathrm{mM})$ and $\alpha$-ketoisocaproic acid $(10 \mathrm{mM})$ caused typical kinetics of FADfluorescence decrease. The results are interpreted to indicate rapid
\end{abstract}

changes of the functional state of B-cell mitochondria induced by the above-mentioned stimulators of insulin release.

Key words: Pancreatic islets, obese-hyperglycemic mice, perifusion, fluorescence, oxidized flavoproteins, D-glucose, L-leucine, (士)-b-BCH, $\alpha$-ketoisocaproic acid.
In pancreatic islets glucose and mannose stimulated insulin release which was accompanied by a rapid increase of the fluorescence of reduced pyridine nucleotides $(\mathrm{NAD}(\mathrm{P}) \mathrm{H})$ [1]. L-leucine, 2-endoaminonorbornane-2-carboxylic acid (b-BCH) and $\alpha$-ketoisocaproic acid (KIC), substances known to trigger insulin secretion in the absence of glucose caused a rapid increase of $\mathrm{NAD}(\mathrm{P}) \mathrm{H}$-fluorescence which took place with typical kinetics [2,3,4]. On the other hand glucagon or L-arginine, which did not stimulate insulin release in the absence of glucose [5], did notinduce a reduction of pyridine nucleotides $[1,3]$.

Evidence was presented that phosphorylation of glucose mediated the glucose induced NAD $(\mathrm{P}) \mathrm{H}-$ fluorescence increase, but it remained unsettled whether the fluorescence increase was recorded from the cytosol or from the mitochondrial space [1]. In studies with the perfused heart and the perfused liver fluorescence of oxidized flavoproteins (FAD) was found to be specific for the mitochondrial space $[6,7$, 8]. Therefore we recorded the fluorescence of FAD when islets were exposed to glucose, leucine, b-BCH or $\mathrm{KIC}$ in order to gain information on the redox state of B-cell mitochondria. Preliminary results of some of the following observations have been reported elsewhere [9].

\section{Materials and Methods}

\section{Chemicals}

The following substances, which contained no fluorescent impurities, were used: L-leucine from Ser- va, Heidelberg; sodium salt of $\alpha$-ketoisocaproic acid from Sigma, St. Louis. ( \pm )-b-BCH was prepared as described [10]. All other substances were obtained from Merck, Darmstadt.

\section{Perifusion of Pancreatic Islets}

6-8 month old obese-hyperglycemic mice of both sexes were starved for 20-28 h and killed by decapitation. The mice are bred in our institute since 1966 and are a non-inbred strain. Pancreatic islets were dissected within 10 min at $+2^{\circ}$ in Krebs-Ringer phosphate buffer [11] containing $3.3 \mathrm{mM}$ glucose and gassed with $\mathrm{O}_{2}$ [12].

The perifusion technique previously described [13, 14] was modified. The perifusion chamber $(1.0 \mathrm{~mm}$ inner diameter) was placed in a small block of aluminium which was mounted on the movable stage of a microscope. The block was kept at $+36.5^{\circ}$ by water circulating through bores in the block. The perifusion chamber and a four way valve (Labotron, Gelting) without dead space ( $0.5 \mathrm{~mm}$ bore diameter) were connected by a polythene tube $(0.2 \mathrm{~mm}$ inner diameter). The valve selected the medium flowing through the chamber at $85 \mu \mathrm{l} / \mathrm{min}$. The media were pumped by a two-channel pumping system (Perpex, LKB, Stockholm). The time the medium travelled from the valve to the top of the chamber was $25 \mathrm{sec}$. It took $23 \mathrm{sec}$ for the medium at the top of the perifusion chamber to change its concentration by $90 \%$ of the way to a new steady-state. The media consisted of Krebs-Ringer bicarbonate buffer [15]. Fluorescence 
or insulin release were measured in parallel experiments. Each experiment was repeated 5 times using different islets $(0.3-0.4 \mathrm{~mm}$, longest diameter, $0.2-$ $0.3 \mathrm{~mm}$ shortest diameter). The typical effects on fluorescence and insulin release were always seen.

\section{Analytical}

A microscope (Orthoplan, Leitz, Wetzlar) was equipped with a light measuring unit (MPV, Leitz, Wetzlar; photomultiplier type EMI 9524 B) and an "epi"-illumination system (Fluoreszenzopak with Apochromat $12.5 \times$, Leitz, Wetzlar). The multiplier output was fed to a recorder (KA-40, Rikadenki, Tokio), equipped with an event marker which was connected to the four way valve positions. Fluorescence was excited by air-cooled mercury arcs (HBO $100 \mathrm{~W} / 2$, Osram, Berlin, for FAD; ST 41, Original Hanau, for NAD(P)H). Primary filter for FAD excitation was a combination of $436 \mathrm{~nm}$ Eppendorf (Netheler and Hinz, Hamburg), $4 \mathrm{~mm} \mathrm{BG} 38$ and $2 \mathrm{~mm} \mathrm{KG} 1$ (Schott, Mainz). Primary filter for $\mathrm{NAD}(\mathrm{P}) \mathrm{H}$ excitation was a combination of $2 \mathrm{~mm}$ UG 1, $4 \mathrm{~mm}$ BG 38 and $2 \mathrm{~mm} \mathrm{KG} 1$ (Schott, Mainz). Secondary filters were Leitz K 510 (FAD) and Leitz K $430(\mathrm{NAD}(\mathrm{P}) \mathrm{H})$. The time constant of the light measuring set-up was $3 \mathrm{sec}$. About $30 \%$ of the fluorescence ( $436 \mathrm{~nm}$ excitation, $>510 \mathrm{~nm}$ emission) or $50 \%$ of the fluorescence ( $366 \mathrm{~nm}$ exitation, $>400$ $\mathrm{nm}$ emission) recorded from islets perifused without substrate derived from the perifusion chamber material. Immunologically reactive insulin was measured as described [16] using ox insulin as standard.

\section{Results}

Unlike the couple NAD(P)H/NAD(P), reduced flavoproteins are nonfluorescent and oxidized flavoproteins fluoresce $(436 \mathrm{~nm}$ excitation, $>510 \mathrm{~nm}$ emission) [8]. When pancreatic islets perifused with $5 \mathrm{mM}$ glucose were suddenly exposed to $20 \mathrm{mM}$ glucose, fluorescence of FAD decreased (Fig. 1) indicating a reduction of oxidized flavoproteins which paralleled the reduction of pyridine nucleotides (Fig. 2). The FAD-fluorescence decrease began $10 \mathrm{sec}$ after arrival of the medium rich in glucose at the islet and reached a new steady state within 4 min (Fig. 1). Taking into account the $15 \mathrm{sec}$ time constant of medium change at the islet and the glucose diffusion across the islet tissue, the onset of FAD-fluorescence decrease reflects redox changes of flavoproteins starting a few seconds after exposure of islet cells to a high glucose concentration. Withdrawal of glucose reversed the FAD-

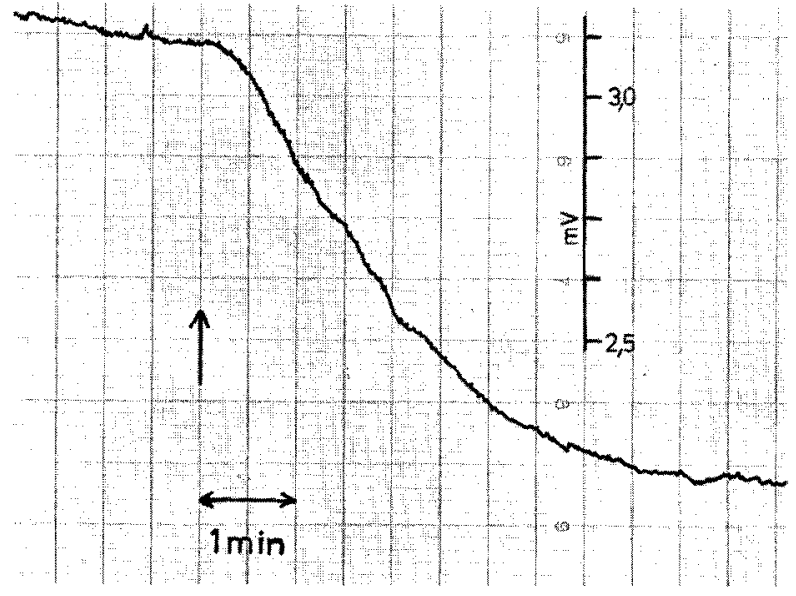

Fig. 1. Effect of $20 \mathrm{mM}$ D-glucose on FAD-fluorescence trace of a single islet $(0.20 \mathrm{~mm}$ shortest diameter) which was perifused previously with $5 \mathrm{mM}$ glucose. The arrow marks the moment when the medium containing $20 \mathrm{mM} \mathrm{D}$-glucose arrived at the islet. A downward deflection of the trace represents a decrease of the fluorescence light (recorded as $\mathrm{mV}$ )

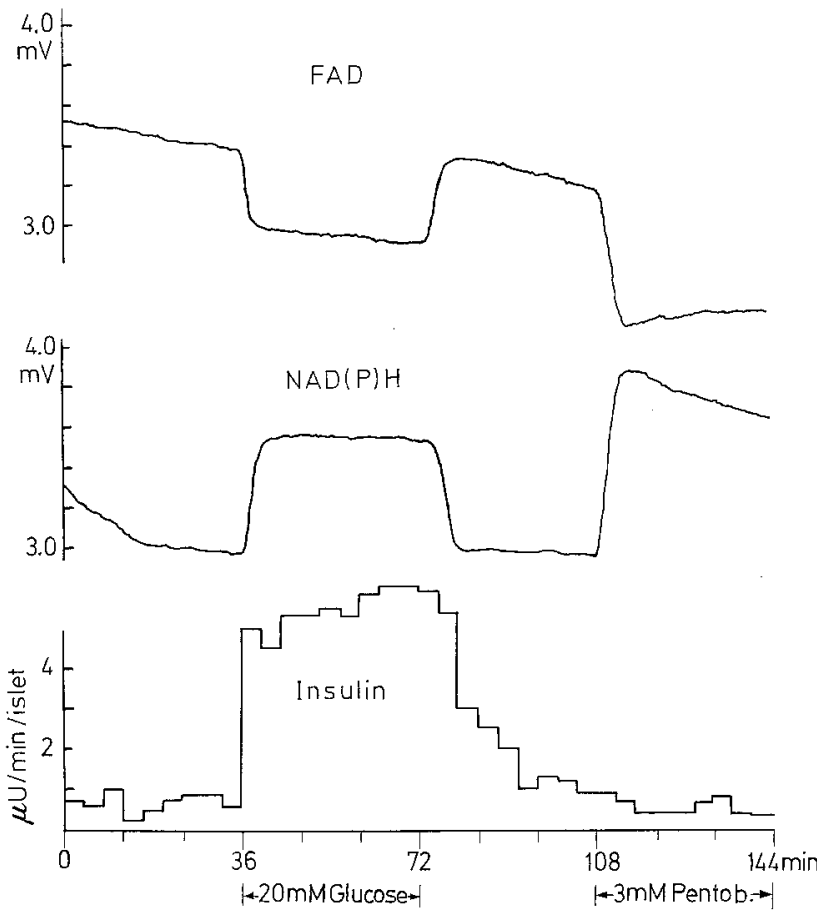

Fig. 2. Effects of D-glucose and pentobarbital on FAD-fluorescence (curve a), NAD(P)H-fluorescence (curve b) and insulin release (curve c) from single perifused islets. Each curve represents one of five experiments performed under the same conditions. All experiments gave similar profiles. A downward deflection of traces a or $b$ represents a decrease of the fluorescent light (recorded as $\mathrm{mV})$ 


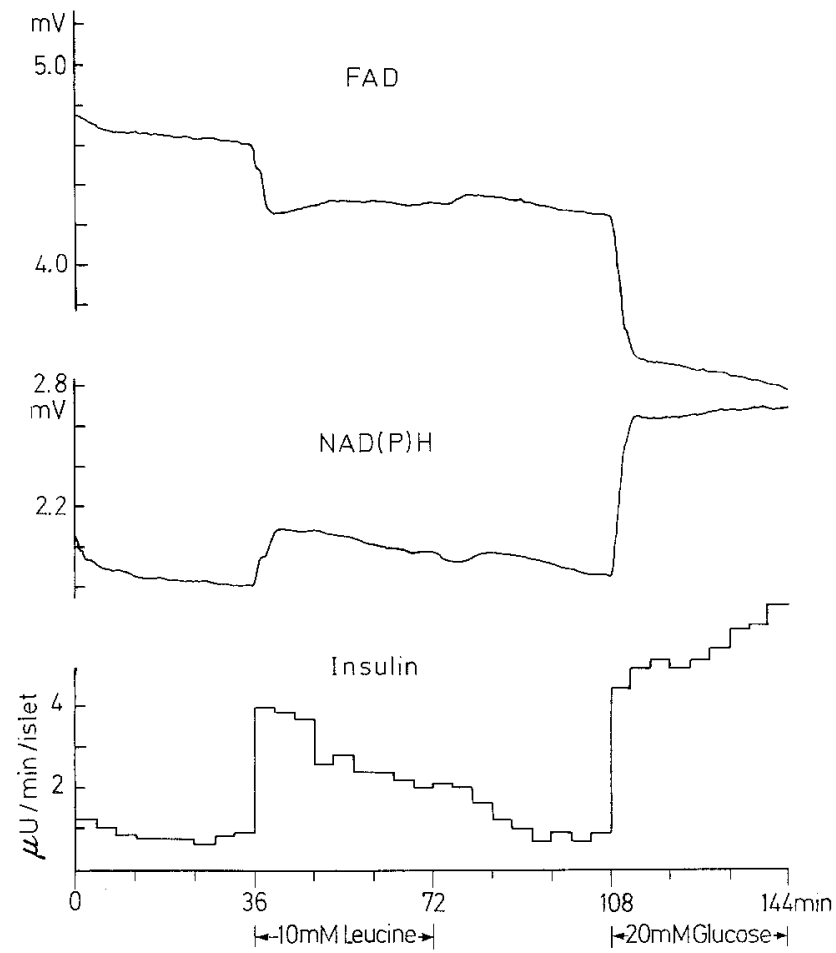

Fig. 3. Effect of L-leucine on FAD-fluorescence (curve a), NAD(P) H-fluorescence (curve b) and insulin release (curve c) from single perifused islets. Each curve represents one of five experiments performed under the same conditions. All experiments gave similar profiles. A downward deflection of traces a or b represents a decrease of the fluorescent light (recorded as $\mathrm{mV}$ )

fluorescence decrease (Fig. 2). By blocking the respiratory chain, pentobarbital induced an accumulation of reduced pyridine nucleotides in pancreatic islets [1]. Fig. 2 shows that the pentobarbital-induced increase of $\mathrm{NAD}(\mathrm{P}) \mathrm{H}$-fluorescence is accompanied by a decrease of the FAD-fluorescence.

L-leucine $(10 \mathrm{mM})$ or $( \pm)$ b-BCH $(20 \mathrm{mM})$ caused a two-step decrease of the FAD-fluorescence, which started $15 \mathrm{sec}$ after medium change began and reached its minimum 3 min later (Figs. 3 and 4 ). These kinetics resembled strikingly the redox transitions of the pyridine nucleotides. When switching from a medium without substrate to a medium supplemented with $10 \mathrm{mM}$ KIC a FAD-fluorescence decrease started $15 \mathrm{sec}$ after KIC arrived at the islet and reached its overshooting minimum about 3 min later (Fig. 5). Then the fluorescence increased again, approaching the prestimulatory level when considering the gradual decrease of the fluorescence baseline and the small fluorescence increase after withdrawal of $\mathrm{KIC}(10 \mathrm{mM})$. Also in the case of KIC the kinetic of FAD-reduction was accompanied by a corresponding kinetic of NAD(P)-reduction (Fig. 5).
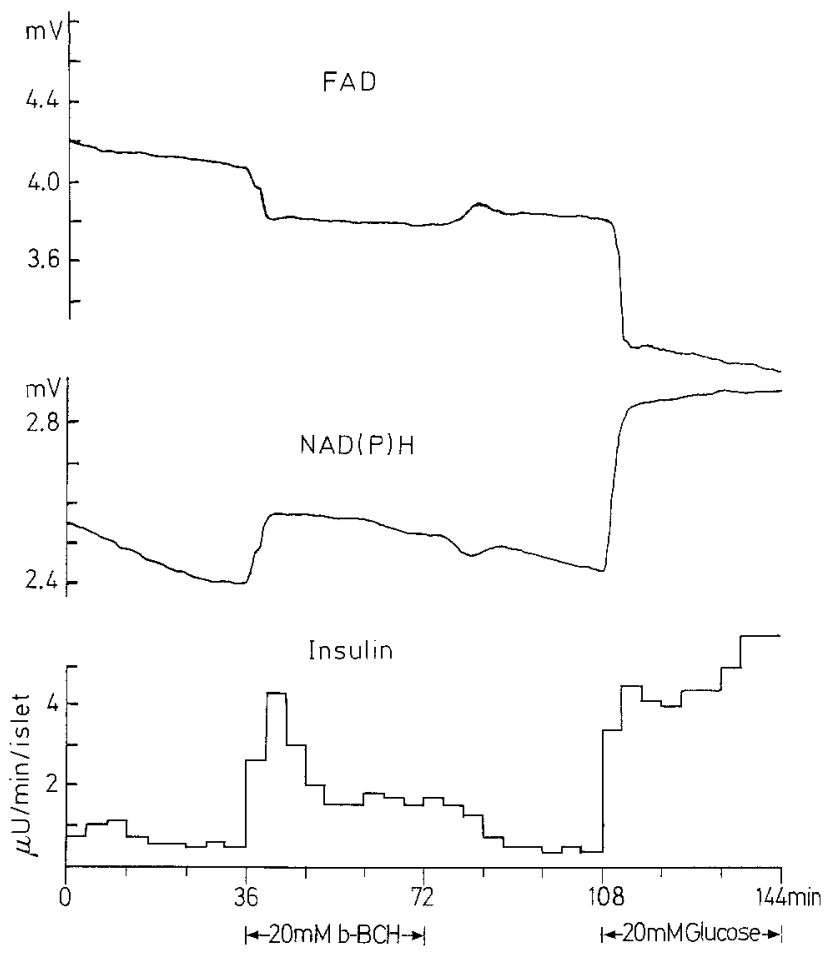

Fig. 4. Effect of $( \pm)-b-B C H$ on FAD-fluorescence (curve a), $\mathrm{NAD}(\mathrm{P}) \mathrm{H}$-fluorescence (curve b) and insulin release (curve c) from single perifused islets. Each curve represents one of five experiments performed under the same conditions. All experiments gave similar profiles A downward deflection of traces a or b represents a decrease of the fluorescent light (recorded as $\mathrm{mV}$ )

L-arginine-induced insulin release was not accompanied by significant changes of the FAD- or NAD(P)H-fluorescence traces (Fig. 6).

\section{Discussion}

The present results demonstrate that changes of the NAD(P)H-fluorescence from pancreatic islets are accompanied by corresponding changes of the FADfluorescence. Since FAD-fluorescence from liver is specific for the mitochondrial space [8], there is no reason to believe that islet cell $\mathrm{FAD}$-fluorescence does not originate from mitochondria unless high microsomal FAD-fluorescence has been shown in pancreatic islets. Moreover, it is possible that, similar to cardiac muscle [17], the $\mathrm{NAD}(\mathrm{P}) \mathrm{H}$-fluorescence mainly indicates the redox state of pyridine nucleotides from islet mitochondria.

In cardiac muscle the FAD-fluorescence signal is derived from the top $0.84 \mathrm{~mm}$ [7]. In our experiments the depth of islet tissue was less than $0.3 \mathrm{~mm}$. Therefore all cell layers contributed appreciably to the 


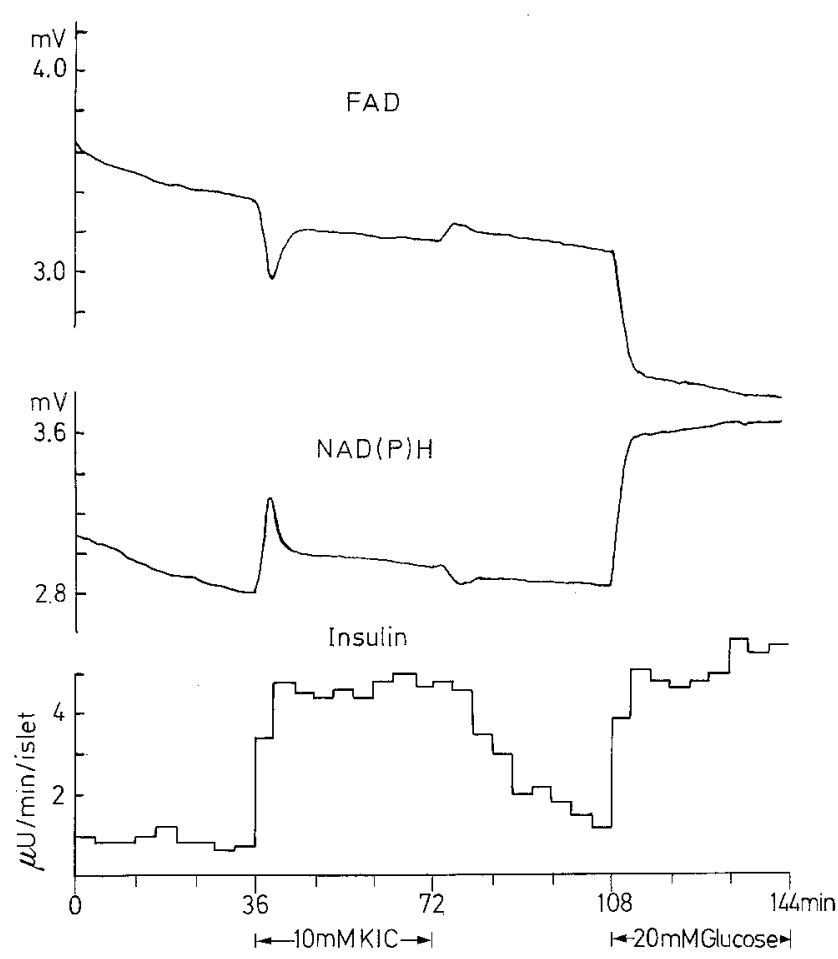

Fig. 5. Effect of KIC on FAD-fluorescence (curve a), NAD(P)Hfluorescence (curve b) and insulin release (curve c) from single perifused islets. Each curve represents one of five experiments performed under the same conditions. All experiments gave similar profiles. A downward deflection of traces $a$ or $b$ represents a decrease of the fluorescent light (recorded as $\mathrm{mV}$ )

FAD-fluorescence from islets of obese-hyperglycemic mice, which contain more than $90 \%$ B-cells [18]. The results are therefore representative of B-cell mitochondria. Recording of the redox state of flavoproteins gives, for the first time, information about rapid changes of islet mitochondrial metabolism. Oxygen consumption of single pancreatic islets has been measured using the cartesian diver technique [19]. But time resolution of the latter method is too small to measure $\mathrm{O}_{2}$-consumption during intervals shorter than a few min.

$\mathrm{NAD}(\mathrm{P}) \mathrm{H}-\mathrm{fluorescence}$ changes in response to glucose, leucine, $\mathrm{BCH}$ or $\mathrm{KIC}$ did not reflect simply stimulated beta-granule exocytosis or enhanced proinsulin synthesis $[1,3,4]$. Therefore, the reported changes of $\mathrm{NAD}(\mathrm{P}) \mathrm{H}$ - and FAD-fluorescence may be caused by effects of stimulators upon islet cell membranes resulting in altered adenylcyclase activity, ion redistributions, a change of the phosphate potential or various combinations of these effects. In the electric organ of the eel, in the rat ganglion or in the rabbit vagus nerve stimulation of ion fluxes have been shown to bring about rapid responses of NAD(P)H-fluores-

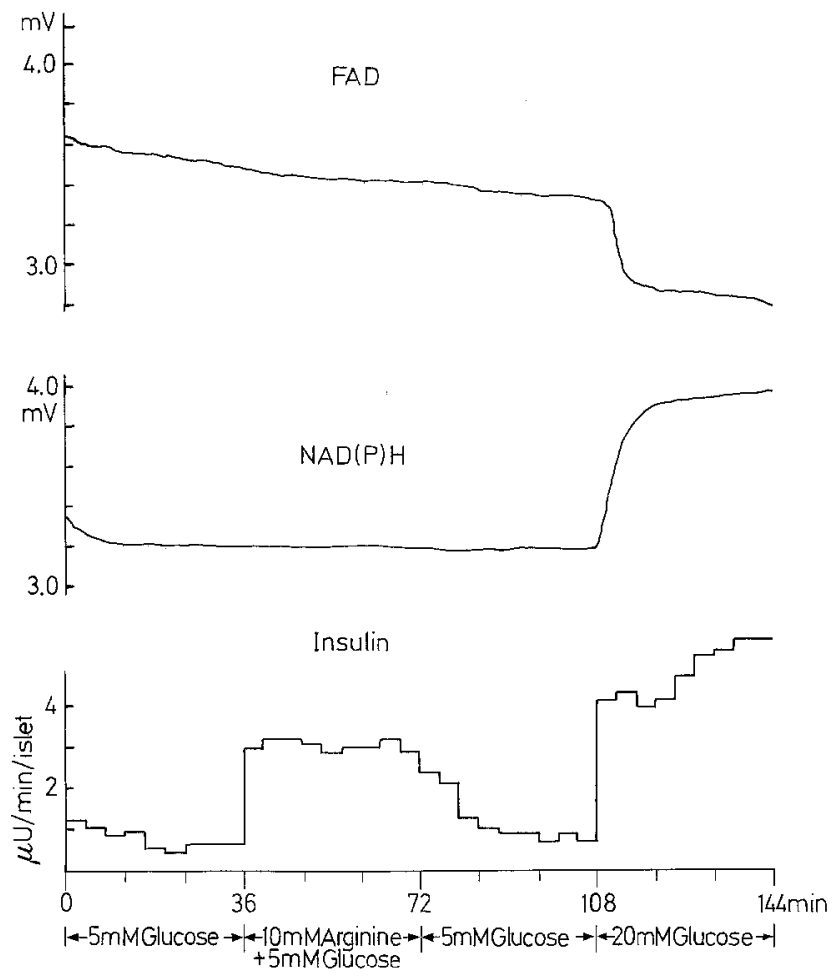

Fig. 6. Effect of L-arginine on FAD-fluorescence (curve a), NAD(P)H-fluorescence (curve b) and insulin release (curve c) from single perifused islets. Each curve represents one of five experiments performed under the same conditions. All experiments gave similar profiles. A downward deflection of traces a or b represents a decrease of the fluorescent light (recorded as $\mathrm{mV}$ )

cence by activation of glycogenolysis, glycolysis or oxidative phosphorylation $[20,21,22]$. The fluorimetric responses to the nonmetabolized $\mathrm{BCH}$ or to leucine probably reflect similar mechanisms [3,4]. Glucose may bring about additional stimulation of glycolysis by its phosphorylation [1], thus enhancing production of reducing equivalents which are rapidly transferred to the mitochondrial space.

Whatever is the detailed mechanism of FADreduction by glucose, leucine, $\mathrm{BCH}$ or $\mathrm{KIC}$, the demonstration of altered mitochondrial function within seconds after exposure of pancreatic islets to those triggers of insulin release, suggests the participation of mitochondria in stimulus-secretion coupling in B-cells. Calcium release from rat liver mitochondria could be elicited by the glycolytic metabolite phosphoenolpyruvate [23]. On the other hand it has been proposed that mitochondria play a role in the beat to beatregulation of $\mathrm{Ca}^{++}$in heart [24]. That hypothesis was supported by the finding that the affinity of heart mitochondria for calcium exceeds that of troponin [25]. In view of the similarities between excitation-contraction coupling and stimulus-secretion coupling [26], mitochondria 
may also take part in the rapid regulation of the cytosolic calcium concentration of B-cells.

Acknowledgements. This investigation was supported by the Deutsche Forschungsgemeinschaft.

\section{References}

1. Panten, U., Christians, J., v. Kriegstein, E., Poser, W., Hasselblatt, A.: Effect of carbohydrates upon fluorescence of reduced pyridine nucleotides from perifused isolated pancreatic islets. Diabetologia 9, 477-482 (1973)

2. Panten, U., v. Kriegstein, E., Poser, W., Schönborn, J., Hasselblatt, A.: Effect of L-leucine and $\alpha$-ketoisocaproic acid upon insulin secretion and metabolism of isolated pancreatic islets. FEBS Letters 20, 225-228 (1972)

3. Panten, U., Christians, J.: Effects of 2-endo-aminonorbornane-2-carboxylic acid upon insulin secretion and fluorescence of reduced pyridine nucleotides of isolated perifused pancreatic islets. Naunyn-Schmiedeberg's Arch. Pharmacol. 276, 55-62 (1973)

4. Panten, U., Christians, J., v. Kriegstein, E., Poser, W., Hasselblatt, A.: Studies on the mechanism of L-leucine- and $\alpha$-ketoisocaproic acid-induced insulin release from perifused isolated pancreatic islets. Diabetologia 9, 149-154 (1974)

5. Panten, U.: Amino acids and insulin secretion. In: Handbuch der exp. Pharmakologie, Vol. 32/2, pp. 115-128. BerlinHeidelberg-New York: Springer 1975

6. Chance, B., Mayer, D., Rossini, L.: A time-sharing instrument for direct readout of oxidation-reduction states in intra-cellular compartments of cardiac tissue. JEEE. Trans. Biomedical Eng. 17, 118-121 (1970)

7. Chance, B., Salkovitz, J. A., Kovach, A. G. B.: Kinetics of mitochondrial flavoprotein and pyridine nucleotide in perfused heart. Amer. J. Physiol. 223, 207-218 (1972)

8. Scholz, R., Thurman, R. G., Williamson, J. R., Chance, B., Bücher, Th.: Flavin and pyridine nucleotide oxidation-reduction changes in perfused rat liver. I. Anoxia and subcellular localization of fluorescent flavoproteins. J. biol. Chem. 244, 2317-2324 (1969)

9. Panten, U., Ishida, H.: Flavin fluorescence of isolated pancreatic islets. Naunyn-Schmiedeberg's Arch. Pharmacol. Suppl. 282, R 73 (1974)

10. Tager, H. S., Christensen, H. N.: 2-Aminonorbornane-2-carboxylic acid. Preparation, properties and identification of the four isomers. J. Amer. chem. Soc. 94, 968-972 (1972)

11. Umbreit, W. W.: Methods for preparation and study of tissue. In: Manometric techniques ed. W.W.Umbreit, R.H. Burris, J. F. Stauffer, p. 135. Minneapolis: Burgess Publ. Co. 1957
12. Hellerström, C.: A method for the microdissection of intact pancreatic islets of mammals. Acta endocr. (Kbh.) 45, 122-132 (1964)

13. Panten, U., dal Ri, H., Poser, W., Hasselblatt, A.: Eine Methode der Gewebsumströmung für Fluoreszenzmessungen. Pflügers Arch. ges. Physiol. 323, 86-90 (1971)

14. Panten, U.: Untersuchungen über Stoffwechsel und Insulinsekretion isolierter Pankreasinseln. Habilitationsschrift Universität Göttingen 1971

15. Krebs, H. A., Henseleit, K.: Untersuchungen über die Harnstoffbildung im Tierkörper. Hoppe-Seylers Z. physiol. Chem. 210, 33 (1932)

16. Zaharko, D. S., Beck, L. V.: Studies of a simplified plasma insulin immunoassay using cellulose powder. Diabetes 17, $444-457$ (1968)

17. Chapman, J. B.: Fluorometric studies of oxidative metabolism in isolated papillary muscle. J. gen. Physiol. 59, 135-154 (1972)

18. Hellmann, B.: Studies in obese-hyperglycemic mice. Ann. N. Y. Acad. Sci. 131, 541-558 (1965)

19. Hellerström, C.: Effects of carbohydrates on the oxygen consumption of isolated pancreatic islets of mice. Endocrinology 81, 105-112 (1967)

20. Aubert, X., Chance, B., Keynes, R. D.: Optical studies of biochemical events in the electric organ of Electrophorus. Proc. roy. Soc, B 160, 211-245 (1964)

21. Brauser, B., Bücher, Th., Dolivo, M.: Redox transitions of cytochromes and pyridine nucleotides upon stimulation of an isolated ganglion. FEBS Letters 8, 297-300 (1970)

22. Landowne, D., Ritchie, J. M.: On the control of glycogenolysis in mammalian nervous tissue by calcium. J. Physiol. 212, 503-517 (1971)

23. Peng, C. F., Price, D. W., Bhuvaneswaran, C., Wadkins, C. L.: Factors that influence phosphoenolpyruvate-induced calcium efflux from rat liver mitochondria. Biochem. biophys. Res. Commun. 56, 134-141 (1974)

24. Patriarca, P. L., Carafoli, E.: A study of the intracellular transport of calcium in rat heart. J. cell. comp. Physiol. 72, 29-38 (1968)

25. Carafoli, E., Dabrowska, R., Covetti, F., Tiozzo, R., Drabikowski, W.: An in vitro study of the interaction of heart mitochondria with troponin-bound $\mathrm{Ca}^{2+}$. Biochem. biophys. Res. Commun. 62, 908-912 (1975)

26. Douglas, W. W.: Stimulus-secretion coupling: The concept and clues from chromaffin and other cells. Brit. J. Pharmacol. 34, 451-474 (1968)

Dr. U. Panten

Institut für Pharmakologie und

Toxikologie der Universität Göttingen

Geiststr. 9

D-34 Göttingen

Federal Republic of Germany 